\title{
Impact of Stress on Human Body: A Review
}

\author{
Muhammad Shahid Zafar, Museera Nauman, Hina Nauman, Sheema Nauman, Asifa Kabir, \\ Zunaira Shahid, Anam Fatima, and Maria Batool
}

\section{ABSTRACT}

Every inherent or external incentive which involves natural reactions is recognized as stress. Extenuatory reaction to these pressures is known as stress reactions. Stress contributes to broad variety of diseases including hypertension and superior plasma cortisol, cardiac and CVDs, inflammatory bowel syndromes, type 2 diabetes, and a reduced quality of life among those suffering with cancer. Stress happens in 3 stages. The first stage is an initial stage of alarm, which produces an increase of adrenaline. Living organisms can withstand intense stress and stay alive. Second phase is a brief conflict process that the body puts up to handle the problem. Last phase is the tiredness phase, which arises when the body has utilized every part of its accessible assets. Stress affects the different organs of the whole body. As far as chronic stress is concerned, it stimulates infection in the vasculature, particularly in the coronary arteries, also can alter cholesterol levels and excessive activation of sympathetic nervous system (depletes the system of neurotransmitters, peptides, cofactors, and other mediators). Regarding, endocrine stress, it affects the hypothalamus in brain. The stress condition in $n$ individuals experiencing pressure needs a healthy and regular eating including important supplements, moreover, physical exercise and mind rest are regularly suggested for averting stress induced anxiety-linked objections and disease.

Keywords: Cardiovascular system, immunity, Stress, Memory, Bowl Disease.
Submitted : April 21, 2021

Published : May 30, 2021

ISSN: $2593-8339$

DOI: 10.24018 /ejmed.2021.3.3.821

\section{Shahid Zafar}

The University of Agriculture, Peshawar, Pakistan.

(e-mail: shahidzafar478@gmail.com)

Museera Nauman

The University of Agriculture, Peshawar, Pakistan.

(e-mail: museeranauman56@gmail.com)

Hina Nauman

The University of Agriculture, Peshawar, Pakistan.

(e-mail: hinanauman44@gmail.com

Sheema Nauman

The University of Agriculture, Peshawar, Pakistan.

(e-mail: sheemanauman44@gmail.com) Asifa Kabir

Government College University

Faisalabad, Pakistan.

(e-mail: asifakabir4679@gmail.com)

Zunaira Shahid

The University of Agriculture, Peshawar, Pakistan.

(e-mail: zararao719@gmail.com)

Anam Fatima

Riphah International University, Islamabad.

(e-mail: anamfatima2103@gmail.com)

Maria Batool

Huazhong Agriculture University, Wuhan, China.

(e-mail: mariabatool633@yahoo.com)

*Corresponding Author

\section{INTRODUCTION}

Stress is referred as a condition in which mind responses by some biochemical processes within body, resulted in anxiety and depressed as well as tensed situation due to external and external factors [1]. Moreover, it happened at the time of lack of recourses to meet the requirement in the body, stress is an uninvited part throughout human lifespan and experienced even before birth. Stress with limited level affected positivity for human survival. Support from blood relations is compulsory for children to learn how to respond stress in a physically and emotionally healthy manner. In many cases, the pathosphysiological complications of disease occur from stress e.g., those who work or live in stressful environments, have a higher risk of many disorder
[2]. In light of the short, timing and seriousness of the upgrade, stress can utilize different activities on the body from moving homeostasis to dangerous impacts and demise [3].

There are three categories of stress that the National Scientific Council on the Developing Child has recognized founded on available research, which included positive stress, tolerable stress, and toxic stress. Positive stress result after undesirable events which are bit lived. Children may clash with optimistic anxiety after they join a fresh daycare, meet different individuals, or may a toy take away from them [1]. This type of stress causes minimal functional changes including variation in hormonal levels. With the support of gentle adults, children can learn how to manage and overcome positive stress [4]. Moreover, tolerable stress 
refers to adverse events that are more intense but still comparatively short-lived. If a child has the support of a caring adult, tolerable stress can usually be overcome [5]. Additionally, toxic stress results from intense adverse encounters that may be suffered across a prolonged interval of time weeks, months or even years [1]. Appropriate support and intervention can help in restoring the stress response system back to its normal baseline [6]. There is substantial evidence that stress can affect an individual's health, not only through direct physiological processes but also by changing behaviors that affect health [7], [8].

The QoL (quality of life) is the general well-being of individuals and societies and is associated with broad variety of contexts; it often includes physical, psychological, social relationships, and environmental aspects [7]. In earlier experiments concerning apparent stress and QoL among campus pupils, apparent stress was adversely associated with QoL [9], [10]. Furthermore, a recent systematic review of 13 studies highlighted that apparent stress and quality of life showed a significant negative association in university students and that continuous perceived stress had effects that went beyond health commitment and QoL [11]. Moreover, the effects of stress on human immune system, digestive system, central nervous system, and cardiovascular system are well pronounced (Fig. 1), furthermore, detailed information is provided in our literature.

The impacts of anxiety on nervous system have been examined for 50 years. Some experiments have suggested that stress has many impacts on the human nervous system and can cause mechanical changes on various parts of the brain. Constant pressure can prompt decay of the cerebrum mass abatement its weight. These underlying changes achieve contradictions in the reaction to stress, cognition, and memory [3].

Memory is the essential operating facets of the CNS and it is classified as tactile, bit term and long term. Transient memory is subject to the capacity of the anterior and parental flaps, while long haul retention varies upon the capacity of huge regions of the cerebrum [12].

Stress also has negative effects on learning. Results from hippocampus-dependent leading records explain that studies are not recognizable with a new atmosphere after visible to a different atmosphere. Additionally, adrenal steroids run to variation in long-term potentiating, which is important process in memory development [13].

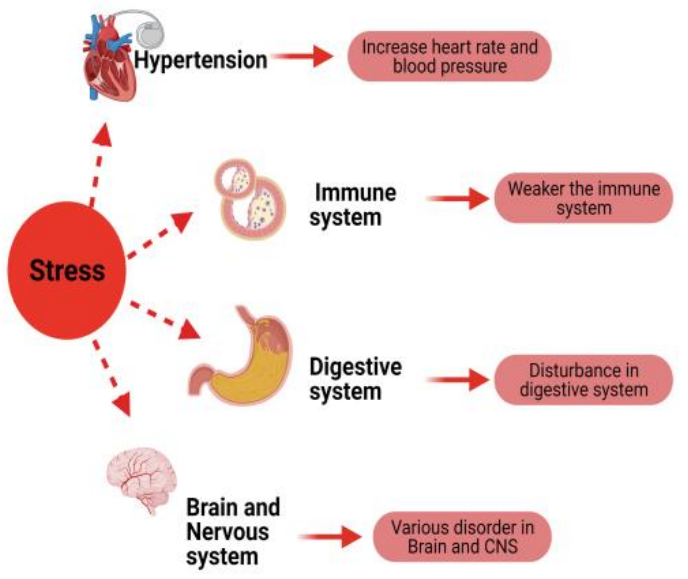

Fig. 1. Stress impacts on human immune system, digestive system, central nervous system, and cardiovascular system.
Stress also effects immune system. At some stage in stress, the immune system's ability to fight off antigens is reduced. A person with stress is more at risk to infections. The stress hormone corticosteroid can destroy the efficacy of the immune system [12]. Moreover, it can contribute to long term problems for heart and blood vessels e.g., heart rate, blood pressure and stock [14]. Recurrent severe anxiety and constant prolonged anxiety likewise impact to infection in the cardiovascular scheme, especially in the coronary arteries, this route led to heart attack [15].

This study described several main impacts of anxiety on the central biological scheme of human being.

\section{STRESS AND BRAIN COMPLICATION}

The brain and adrenal are vital control centers that maintain body homeostasis under basal and stress conditions and coordinate the body's response to stress. Those who have anxiety-associated syndromes demonstrate heightened sensitivity to psychological disease [16].

Glucocorticoids delivered throughout pressure, probably working across the hippocampus, might clarify partially the intensely changeable just as persistent impacts that anxiety has on explanatory reminiscence [17]. Anxiety starts in the mind and disturbs the cerebrum, just as the remainder body. Severe anxiety reactions encourage variation and endurance by mean of reactions of nervous, cardiac, self-governing, protected, and metabolic procedures. Persistent anxiety can encourage and exasperate pathophysiology via the similar methods that are liberated [18].

The incapability to deal with life events, which leads to the hyper secretion of corticosteroids, imposes an increased risk for depression, as well as increased abdominal obesity, osteoporosis, and cardiovascular problems [19]. Damaged seleno-protein production because of changes SepSecSquality produces Developing Cerebro-Cerebellar Atrophy (PCCA), which is an autosomal passive issue bringing about extreme cerebrum irregularities [20]. As the disease gradually worsen, many secondary symptoms develop, such as postural instability; difficulty in swallowing, breathing, and speaking; sleep disturbance; depression and dementia [21]. Recently, an increasing number of in vitro and in vivo studies have suggested that oxidative stress has an involvement in autosomal assertive hereditary $\mathrm{AD}$ with changes in amyloid $\beta$ protein precursor (A $\beta$ PP), presenilin-1 (PS-1), or presenilin-2 (PS2) genes [22].

\section{A. Stress and Memory}

Stress affects several neural pathways and mind frameworks that are basic for rambling memory. Such as, stress firstly applies quick impacts in the brain by assemble a flood in both dopamine and noradrenergic action inside the prefrontal cortex [20]. Delayed presentation to glucocorticoids (e.g., because of enduring anxiety for a time of weeks to years) can be particularly hurtful, prompting shrinkage of pyramidal neurons in the hippocampus and in the frontal, pre/postcentral, and cingulate gyri in nonhuman primates. Chronic stress can debilitate long haul memory [21]. A large body of evidence indicates that stress effects on both memory consolidation and retrieval require concurrent 
glucocorticoid and noradrenergic activity in the basolateral part of the amygdala Glucocorticoids that are released during stressful episodes can voluntarily cross the blood-brain blockade and fix to mineralocorticoid receptors and glucocorticoid receptors in limbic brain areas.

On the contrary, catecholamines cannot pass the bloodbrain barrier; they activate adrenoceptors on vagal afferents terminating in the nucleus tractus solitaries. The most direct prediction about episodic memory from consolidation theory is that post-encoding stress should facilitate consolidation of recently encoded events, and so it should slow forget. In addition, the role of the amygdala in supporting emotional memory, and its sensitivity to both the noradrenergic and corticosteroid responses to stress, it can also be expected that stress should have its greatest effects on memory for emotional or arousing materials [23]. The role of cortisol in potentially mediating stress effects on memory has been used to explain why stress effects on memory are sometimes not observed in certain conditions. For example, males exhibit more robust cortisol responses to common laboratory stressors [40]. They have sometimes been found to exhibit more pronounced stress effects on memory [12]. During stressful experiences, numerous hormones, peptides, and neurotransmitters are released [25].

\section{Stress, COGNITION AND LEARNING}

Cognition is an essential function of human body. Cognition means reception and perception of conserved stimuli and its analysis, which includes learning and decision making, attention and judgment [26]. Stress has many impacts on cognition that depends upon duration, intensity, origin, and magnitude. Comparable to memory, cognition mainly occur in hippocampus, amygdala, and temporal lobe [27]. The behavioral steps undertaken to reduce stress leads to increase in cogitations [3].

In fact, stress activates some physiological function such as autonomic nervous system, central neurotransmitter and neuropeptides system and the hypothalamus pituitary adrenal axis, which have direct effect on neural service involved in data processing [28]. Activation of stress results in production and release of glucocorticosteriod, and they can diffuse through plasma- cerebrum block and exert long term effect on cognition and processing. It appears that bringing subjected to anxiety which affect pathological changes in brain, these alterations can demonstrate as developmental, cognitive and mood disorder [29].

For instance, the adrenal steroid effect the function of hippocampus throughout awareness and energy retrieval in biphasic manner [30]. In chronic stress these steroids can destroy neuron with other stimulatory neurotransmitter. Contact to anxiety can leads to hippocampus disorder related to cognition. Additional stress can lead to genesis of neuron in dentate area of hippocampus [3].

\section{IMPACT OF STRESS ON IMMUNE SYSTEM AND ENDOCRINE SYSTEM}

Immune system and endocrine system are linked with each other. This linkage between the two system regulated the cell mediated and hormonal responses. Stress effect the body' response to infection [31]. Stress increases the amount of white blood cells the in blood. Stress enhances the main and minor reactions of immune system. Intensity of the stress can be measure by the amount of stress hormones secreted or may be by some physiological changes in the body like increase blood pressure and heartbeat [32]. Stress can disturb the work of protected procedure by modulating processes in the CNS and neuroendocrine system. Individuals having anxiety have increased in weakened protected method, consequently, endure from additional common disease [13].

Stress can cause immuno-suppression which may hinder wound healing, increases vulnerability of infections, delay the response of vaccines, and can cause cancer [31].

In any case, proof recommends that the lymphatic framework, asection of the protected framework, likewise assumes a crucial function in delivering go between. mediators. For example, thymus peptides, like thymopoietin and thymosin fraction-5, affect the expansion in ACTH creation [2]. Some research demonstrated that lengthy management of $\mathrm{CRH}$ into the cerebrum ventricles conducts to interruption in the delivery of developmental hormone.

A variety of hormonal changes arise in the body in response to stress. Semen boundaries might be connected to stress, whose presence may decrease luteinizing hormone (LH) and testosterone beating [31]. The incidence of white blood cell (primarily granulocytes) in semen has been associated with extreme male factor infertility cases [33]. Moreover, anxiety can reduce the action of cytotoxic Tlymph cell and natural killer cells then take the lead to development of cancerous cells, chromosomal instability, and cancer extension [3].

\section{STRESS AND THE FUNCTION OF CARDIOVASCULAR SYSTEM}

Psychological stress is highly recognized as an important issue and have the capacity to develop the higher risk for cardiovascular diseases [15]. The preliminary impact of anxiety on heart function is usually on heart rate, then the next effect is on blood pressure. Stress can stimulate the sympathetic nerves system which increase vasocontraction, which can mediate an increase in blood pressure, disorders in blood clotting, rise in blood lipids, vascular change; all of which can cause cardiac arrhythmias and myocardial infraction [3]. Stress contributes to cardiovascular diseases at many stages, including long-term development of heart illness and acute triggering of cardiac events. Chronic stress in private life is correlated with $40-50 \%$ increase in the development of coronary heart disease [15], thus cardiovascular system severely affected by stress condition (Fig. 2).

\section{A. Stress as a Risk Factor for Cardiovascular Diseases}

Psychological tension ultimately precedes to potential conflict in dangerous activities for heart, like smoking and clearly take the lead to encouragement of the neuroendocrine framework [3]. 


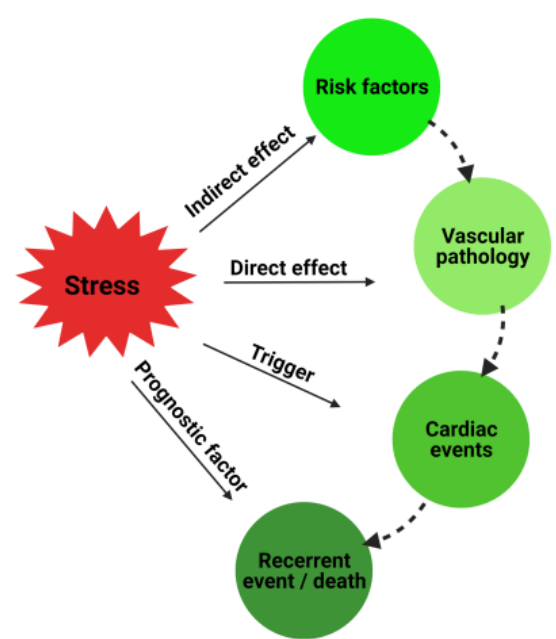

Fig. 2. Stress condition negatively affected the cardiovascular system.

\section{B. Stress-Related Cardiovascular Disease}

Stress can cause cardiovascular disease which can cause death and incapacity globally. According to the international load of infection study, stroke and heart disease accounted for 25\% of the total deaths in the world in 2013 [6]. High level of cortisol form long term stress can increase blood cholesterol, triglyceride levels and blood pressure. These are the common factors for heart disease. Stress can also disturb the blood pressure which may promote the buildup of plaque in the arties [34].

\section{ENTERIC NERVOUS SYSTEM}

\section{A. 'Brain of the GUT'}

Intestinal nervous framework encompasses roughly 100 million nerve cells, which is near the similar amount discovered in the vertebral cord. They involve sensory, motor and interneurons [37]. It creates well to disperse this huge nervous system along the gastrointestinal area, near the effector framework, as opposed to gather it in the focal sensory system (Fig. 3). The ENS and CNS are correlated bidirectional by the thoughtful and the parasympathetic nervous system shaping the mind gut pivot [3].

\section{B. Stress and Gastroesophageal Reflex Disorder}

There is a feeble association among the indicators of stomachache and the proven level of acidic reflux. Equal to $64 \%$ of the tolerant with anxiety and gastroesophageal ebb disorder stated irritation of their signs by anxiety and tension decline actions frequently caused in personal progress [38]. In a study, patient with GERD were split up into two groups: first are those with a propensity to account GI signs throughout emotional suffering (high GI susceptibility) and the second are those who did not have a propensity to account GI sign throughout emotional suffering (low GI susceptibility) [39]. The former group reported more heartbeat associated with experimental stressful tasks even with an equal measured acid exposure in both of the group. It is unrevealed how stress may acerbate the responsive of GERD, peculiarly cardialgia, although systematic alteration of diaphragmatic pinch as a result of change in inhaling and exhaling model, an expand in oropharynx chemosensitivity and a moderate of intestinal outpour by reason of stress potent handout [37]. During the investigation of twenty healthy subjects detect that temporary mental stress obstruct the degrade esophageal sphincter and grow tonic [38].
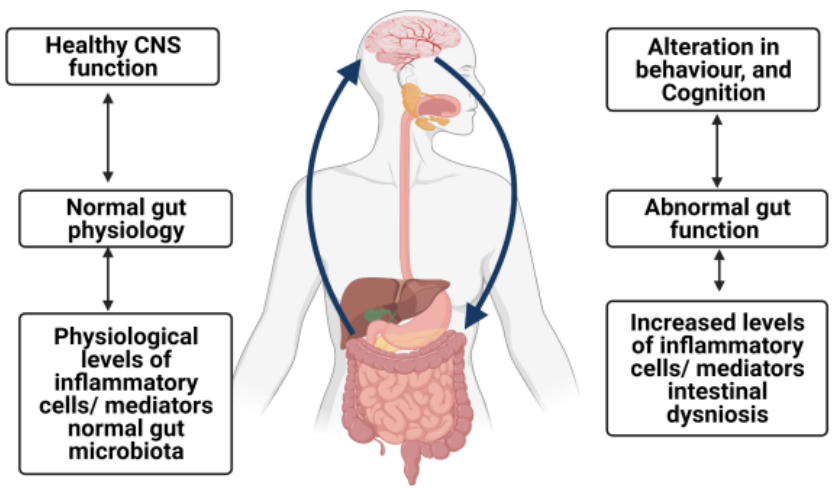

Fig. 3. Negative influence of stress condition on enteric nervous system.

\section{Stress and Functional Dyspepsia}

Nearly all ecological component like smoking, liquor, coffee or apply of anti-steroidal anti-provocative medications are not necessary participation of indigestion [40]. No rare individuality contour has detected in tolerant with operative indigestion, but nervousness, neurosis and unhappiness are superior rampant measure to strong subjects.

In the metabolism experiment, which analyze the predominance of upper GI disease beyond three months amidst 5581 well-being subjects in the generic society, the primary danger is mental stressors, principally newly life occurrence. Every part of life occasion is similar in every subject along with dyspepsia and managed subject [14].

\section{Stress and Peptic Ulcer Disease}

The contents of alliance among peptic ulcer and stress are in man with manage job, those have hither ulcer presence compared to controller. Air passage manager is about increase as likely as resident crew to have ulcers, carefully whose are more stress of levels in the workplace. Duodenal ulcers have been located additional and common in convicted persons of war in the Vietnam war, through look into than in without interested veterans [40]. After the observation of thirty student with ulcer those are checked with thirty measure controls the presence of ulcer in the group has higher and double emotional uproar and distressing life occasion antecedent attack and origin illness.

\section{E. Stress and Inflammatory Bowel Disease}

Inflammatory bowel disease is described by persistent and worsening symptoms. Stress activates the brain axis, the hypothalamic-pituitary-adrenal axis (HPA), autonomic nervous system (ANS) and the whole nervous system (ENS), which contribute to develop inflammatory bowel disease [37]. 1n 1950s, IBW was considered a psychosomatic disorder, and previous studies have recognized a secure interaction between stress and IBW. The patients suffering from IBW are frequently subjected to anxiety, which stimulates feeling changes or starts psychological problems [40]. Major stressors are important in influencing disease activity in IBD. These stressors are not unique and include illness, death in the family, divorce or separation, interpersonal conflict, and major loss [38]. 
TABLE I: STRESS- RELATED CARDIOVASCULAR DISEASE

\begin{tabular}{|c|c|c|c|}
\hline Disease & Causes & Effects & Reference \\
\hline Hypertension & $\begin{array}{l}\text { Anxiety be able to } \\
\text { affect high blood } \\
\text { pressure } \\
\text { frequent via } \\
\text { pressure raises. }\end{array}$ & $\begin{array}{l}\text { Stress have } \\
\text { directly impact on } \\
\text { the development. } \\
\text { Hypertension } \\
\text { effect blood } \\
\text { vessels, heart, and } \\
\text { many body } \\
\text { functions. }\end{array}$ & [14] \\
\hline Atherosclerosis & $\begin{array}{l}\text { High fat diet and } \\
\text { moderate } \\
\text { hyperlipoproteinemi } \\
\text { a can cause } \\
\text { atherosclerosis. }\end{array}$ & $\begin{array}{l}\text { Mechanically } \\
\text { obstructing blood } \\
\text { flow. } \\
\text { Rupture, leading } \\
\text { to thrombosis. }\end{array}$ & [35] \\
\hline $\begin{array}{c}\text { Coronary } \\
\text { Artery disease }\end{array}$ & $\begin{array}{l}\text { Stress is strongly } \\
\text { associated with } \\
\text { CAD. Mental stress } \\
\text { is the serious reason } \\
\text { of angina which } \\
\text { worsen CAD. }\end{array}$ & $\begin{array}{l}\text { CAD develop } \\
\text { heart attack, chest } \\
\text { pain and } \\
\text { arrhythmia. }\end{array}$ & [36] \\
\hline
\end{tabular}

\section{STRESS MANAGEMENT SKILLS}

Some of the best stress relievers are:

\section{A. Eat a Balance Diet}

A mediocre diet can bring bigger responsiveness toward stress. Emotional eating for high fat, high sugar food can provide a momentary sense of relief that adds to long term stress. Refined carbohydrates e.g., cookies and potatoes chips, can increase the blood sugar level. When the body sugar level is high the stress and anxiety may also increase [41]. One of the main troubles with on-going stress is the reduction of nutrients. Eating a healthy diet help to overcome the stress.

Stress builds higher physiological demands. Individuals who are experiencing anxiety require additional nutritionally heavy food but frequently for comfort deficient in the essential nutrients [42]. Stress can cause unhealthy eating habits. It cannot be exaggerated that emotional stress affects all aspects of nutrition [43]. A broad diversity of food needs to be consumed in order to remain healthy. This is because there is not one food available that comprises a lot of essential nutrients that are necessary for ideal health. Consequently, variety of nutritious diets is necessary. Nutrients necessary consist of natural resources, vitamins, proteins, and fatty acids [42]. Consuming required nutrients typically between 40 to 60 nutrients per day is important to a healthy body. Unfortunately, many medical doctors have no background in nutrition, and they deal the patients as a nutritionist [44].

We should eliminate the sugar which is also known as "white killer" from food because it contains no vital nutrients. Sugar may generate a rush of energy for a brief interval. When this high runs out, the person will suffer a collapse [28]. The stress response is fight or flight; either action needs lots of energy. Stress uses many nutrients for energy manufacture.

The following are the main nutrients that the body will use up:

1. B vitamins: This vitamin help the body to deal with stress, build metabolism and control the entire nervous system [42].

2. Proteins: Support in tissue repair, growth, and development [41].
3. Vitamin A: Important for normal vision function [28].

4. Vitamin C: This vitamin protects immune system e. g., antioxidant and diabetes protection, and additionally reduces the quantity of hydrocortisone in the body [45].

5. Magnesium: Required for a range of responsibilities like strength lessening, fatty acid development, creating different compartments, and heartbeat regulation [41].

\section{B. Practice Yoga}

Yoga unites bodily progress, reflection, soft workout, as well asself-controlled breathing, all of which offer excellent stress relief. And while you are likely to gain instant profits after a solo yoga period, you're expected to obtain hung advantages if you merge it for lifetime in a steady direction [46]. Yoga offers a range of natural, emotional, as well as religious advantages. To get started, you might take a class, enroll in an online program, or use an app to help you begin observing [43].

Stress has become a common watchword in our society to reveal a host of difficulties, both as cause and effect [44]. Exercise and complementary treatments are currently regularly suggested for anxiety-linked objections and disease. Just As a latest problem of Consumer Reports recommends that yoga is for anxiety relief. The recommendations for asana practice to change the stress response are different in different traditions [4]. A Yoga practice that focuses only on physical remedies is limited, for it deals only with physiology and not psychology [46].

\section{Use of Mindful Exercise}

Numerous individuals have effectively fought off desires or completely decreased the quantity of "anxiety" diet they consume by observing careful consumption. The demonstration of being available and mindful, can assist individuals with getting the propensity for following up on their yearnings without deduction. Mindfulness workouts are easy to acquire as well as marvelous for boosting flexibility to anxiety in general, so you really cannot lose [47].

Physical activity is key to managing stress and improving mental health. What is more, the greatest report is that there are wide range of sorts of workouts that can diminish your anxiety [44]. Merge With a fitness center, attend a lecture, or workout outdoors. Remember that there are a wide range of approaches to find other actual work in your day as well. Strolling, muscles preparation, kayaking, climbing, and roll class are only a couple various instances of ways you can get pressure help.

It is generally accepted that exercise is beneficial for aging humans as well as patients with Parkinson's disease or Alzheimer's disease [22]. Exercise during pregnancy has been shown to increase hippocampal plasticity in the offspring postnatally. Studies observed that mild prenatal stress (7-hour shift in the light/dark cycle, food deprivation for $24 \mathrm{~h}$, and handling involving moving to new cage and back) reduced strength [1].

\section{CONCLUSION}

Stress is defined as a versatile reaction to an outside circumstance that outcomes in natural, psychological, and developmental variations for administrative participants. 
Stress affects the whole body in different ways. patients surfing anxiety linked diseases demonstrate heightened susceptibility to psychological disease, even centuries later the anxiety familiarity, which is capable to create huge alterations in the brain's structural design as well as working. Stress impacts numerous neural pathways and mind frameworks that are basic for rambling memory. stress has many impacts on cognition that depends upon that depends upon duration, intensity, origin, and magnitude. Alike to remembrance, understanding mainly occur in hippocampus, amygdala, and temporal lobe. Individuals having anxiety have more chances to weakened protected framework, as a consequence, endure from additional recurrent diseases. Psychological stress is highly recognized as an important issue and have the capacity to develop the higher risk for cardiovascular diseases. The initial impact of anxiety on heart function is usually on heart rate, then the next effect is on blood pressure. There is a frail association among the manifestations of indigestion and the proven level of heart burn. Up to $64 \%$ of the people with anxiety and gastroesophageal ebb disorder described irritation of their side effects by anxiety, and anxiety decrease quantifies regularly brought about an emotional progress. Major stressors are important in influencing disease activity in Indianite makes more noteworthy physiological requests. Extra strength, oxygen, movement as well as additional metabolic cofactors are necessary. The incongruity of anxiety is that individuals experiencing pressure require an all the more healthfully thick eating routine yet regularly settle on solace nourishments ailing in the important supplements, therefore encouraging a condition of nutrient exhaustion that additional negotiate the metabolic framework. Yoga joins actual development, reflection, soft workout as well as composed inhalation, all of which give superb anxiety help. Numerous individuals have effectively fought off desires or incredibly diminished the measure of "anxiety" diet they consume by rehearsing careful eating by practicing mindful eating. The demonstration of being available and mindful, can assist individuals with getting the propensity for following up on their yearnings without deduction. Mindful workouts are easy to acquire as well as marvelous for boosting flexibility to stress.

\section{ACKNOWLEDGMENT}

Thanks to Maria Batool from Huazhong Agricultural University, Wuhan, P.R. China. for curious review.

\section{REFERENCES}

[1] Burman R, Goswami TG. A Systematic Literature Review of Work Stress. IJMS. 2018 Jul 1;V(3(9)):112.

[2] Glaser R, Kiecolt-Glaser J. Stress Damages Immune System and Health. Discovery Medicine. 2005;5(26):5.

[3] Yaribeygi H, Panahi Y, Sahraei H, Johnston TP, Sahebkar A. The impact of stress on body function: a review. EXCLI Journal; 16:Doc1057; ISSN 1611-2156 [Internet]. 2017 [cited 2020 Sep 1]; Available from: https://www.excli.de/vol16/Sahebkar_Panahi_21072017_proof.pdf.

[4] Granath J, Ingvarsson S, von Thiele U, Lundberg U. Stress Management: A Randomized Study of Cognitive Behavioural Therapy and Yoga. Cognitive Behaviour Therapy. 2006 Mar;35(1):3-10.

[5] Middlebrooks JS, Audage NC. The Effects of Childhood Stress on Health Across the Lifespan: (721332007-001) [Internet]. American
Psychological Association; 2007 [cited 2020 Sep 25]. Available from: http://doi.apa.org/get-pe-doi.cfm?doi=10.1037/e721332007-001.

[6] Morera LP, Marchiori GN, Medrano LA, Defagó MD. Stress, Dietary Patterns and Cardiovascular Disease: A Mini-Review. Front Neurosci. 2019 Nov 12;13:1226.

[7] Unusan N. Linkage between stress and fruit and vegetable intake among university students: an empirical analysis on Turkish students. Nutrition research. 2006 Aug;v. 26(8):385-90.

[8] Zellner DA, Loaiza S, Gonzalez Z, Pita J, Morales J, Pecora D, et al. Food selection changes under stress. Physiology \& Behavior. 2006;87(4):789-93.

[9] Opoku-Acheampong A. Perceived stress and quality of life of pharmacy students in University of Ghana. 2017;7.

[10] Kleiveland B, Natvig GK, Jepsen R. Stress, sense of coherence and quality of life among Norwegian nurse students after a period of clinical practice. $2015 ; 13$.

[11] Ribeiro ÍJS. Stress and Quality of Life Among University Students_A Systematic Literature Review. Health Professions Education. 2018;8.

[12] Stein M, Miller AH. Stress, the immune system, and health and illness. In: Handbook of stress: Theoretical and clinical aspects, 2nd ed. New York,NY,US: Free Press; 1993. p. 127-41.

[13] Dedovic K, D’Aguiar C, Pruessner JC. What Stress Does to Your Brain: A Review of Neuroimaging Studies. The Canadian Journal of Psychiatry. 2009;54(1):10.

[14] Rosenthal T, Alter A. Occupational stress and hypertension. Journal of the American Society of Hypertension. 2012 Jan;6(1):2-22.

[15] Steptoe A, Kivimäki M. Stress and cardiovascular disease. Nat Rev Cardiol. 2012 Jun;9(6):360-70.

[16] García-Martín R, Alexaki VI, Qin N, Rubín de Celis MF, Economopoulou M, Ziogas A, et al. Adipocyte-Specific HypoxiaInducible Factor $2 \alpha$ Deficiency Exacerbates Obesity-Induced Brown Adipose Tissue Dysfunction and Metabolic Dysregulation. Mol Cell Biol. 2016 Feb 1;36(3):376-93.

[17] Bremner JD, Elzinga B, Schmahl C, Vermetten E. Structural and functional plasticity of the human brain in posttraumatic stress disorder. In: Progress in Brain Research [Internet]. Elsevier; 2007 [cited 2020 Oct 7]. p. 171-86. Available from: https://linkinghub.elsevier.com/retrieve/pii/S0079612307670125.

[18] McEwen A, West R, McRobbie H. Motives for smoking and their correlates in clients attending Stop Smoking treatment services. Nicotine \& Tobacco Res. 2008 May;10(5):843-50.

[19] de Kloet ER, Joëls M, Holsboer F. Stress and the brain: from adaptation to disease. Nat Rev Neurosci. 2005 Jun;6(6):463-75.

[20] Pillai R, Uyehara-Lock JH, Bellinger FP. Selenium and selenoprotein function in brain disorders: Selenium andSelenoprotein Function In Brain Disorders. IUBMB Life. 2014 Apr;66(4):229-39.

[21] Ganguly G, Chakrabarti S, Chatterjee U, Saso L. Proteinopathy, oxidative stress and mitochondrial dysfunction: cross talk in Alzheimer\&\#39;s disease and Parkinson\&\#39;s disease. DDDT. 2017 Mar;Volume 11:797-810.

[22] Jackson EM. STRESS RELIEF: The Role of Exercise in Stress Management. ACSM's Health \& Fitness Journal. 2013;17(3):14-9.

[23] Wassell J, Rogers S, Felmingam KL, Pearson J, Bryant RA. Progesterone and mental imagery interactively predict emotional memories. Psychoneuroendocrinology. 2015 Jan;51:1-10.

[24] Shields GS, Sazma MA, McCullough AM, Yonelinas AP. The effects of acute stress on episodic memory: A meta-analysis and integrative review. Psychological Bulletin. 2017 Jun;143(6):636-75.

[25] Guenzel FM, Wolf OT, Schwabe L. Stress disrupts response memory retrieval. Psychoneuroendocrinology. 2013 Aug;38(8):1460-5.

[26] Sandi C. Stress and cognition: Stress and cognition. WIREs Cogn Sci. 2013 May;4(3):245-61.

[27] Bourne L, Yaroush R. Stress and Cognition:123.

[28] Austin V, Shah S, Muncer S. Teacher stress and coping strategies used to reduce stress. Occup Ther Int. 2005 May;12(2):63-80.

[29] Hämäläinen P, Ikonen A, Romberg A, Helenius H, Ruutiainen J. The effects of heat stress on cognition in persons with multiple sclerosis. Mult Scler. 2012 Apr;18(4):489-97.

[30] LeBlanc VR. The Effects of Acute Stress on Performance: Implications for Health Professions Education: Academic Medicine. 2009 Oct;84(Supplement):S25-33.

[31] Khanam S. Impact of Stress on Physiology of Endocrine System and on Immune System: A Review:3.

[32] Laddha NC, Dwivedi M, Mansuri MS, Gani AR, Ansarullah M, Ramachandran AV, et al. Vitiligo: interplay between oxidative stress and immune system. Exp Dermatol. 2013 Apr;22(4):245-50.

[33] Sajadinejad MS, Asgari K, Molavi H, Kalantari M, Adibi P. Psychological Issues in Inflammatory Bowel Disease: An Overview. Gastroenterology Research and Practice. 2012;2012:1-11. 
[34] Csányi G, Jr. F. Oxidative Stress in Cardiovascular Disease. IJMS 2014 Apr 9;15(4):6002-8.

[35] Esch T, Stefano GB, Fricchione GL, Benson H. Stress in cardiovascular diseases. Clinical Research: 10.

[36] von Känel R, Mills PJ, Fainman C, Dimsdale JE. Effects of Psychological Stress and Psychiatric Disorders on Blood Coagulation and Fibrinolysis: A Biobehavioral Pathway to Coronary Artery Disease?: Psychosomatic Medicine. 2001 Jul;63(4):531-44.

[37] Board F, Persky H, Hamburg DA. Psychological Stress and Endocrine Functions: Blood Levels of Adrenocortical and Thyroid Hormones in Acutely Disturbed Patients. Psychosomatic Medicine. 1956 Jul;18(4):324-33.

[38] Sun Y, Li L, Xie R, Wang B, Jiang K, Cao H. Stress Triggers Flare of Inflammatory Bowel Disease in Children and Adults. Front Pediatr. 2019 Oct 24;7:432.

[39] Mayer EA. The neurobiology of stress and gastrointestinal disease. Gut. 2000 Dec 1;47(6):861-9.

[40] Huerta-Franco M-R. Effects of occupational stress on the gastrointestinal tract. WJGP. 2013;4(4):108.

[41] Gonzalez MJ, Miranda-Massari JR. Diet and Stress. Psychiatric Clinics of North America. 2014 Dec;37(4):579-89.

[42] Osdoba KE, Mann T, Redden JP, Vickers Z. Using food to reduce stress: Effects of choosing meal components and preparing a meal. Food Quality and Preference. 2015 Jan;39:241-50.

[43] Patel GK. The Role of Nutrition in the Management of Lower Extremity Wounds. The International Journal of Lower Extremity Wounds. 2005 Mar;4(1):12-22.

[44] Rizzolo D, Zipp GP, Stiskal D, Simpkins S. Stress Management Strategies for Students: The Immediate Effects of Yoga, Humor, And Reading On Stress. TLC [Internet]. 2011 Jan 10 [cited 2020 Sep 19];6(8). Available from: https://clutejournals.com/index.php/TLC/article/view/1117.

[45] Anand SS, Hawkes C, de Souza RJ, Mente A, Dehghan M, Nugent R, et al. Food Consumption and its Impact on Cardiovascular Disease: Importance of Solutions Focused on the Globalized Food System. Journal of the American College of Cardiology. 2015 Oct:66(14):1590-614.

[46] Serber E. Stress Management through Yoga:6.

[47] Varvogli L, Darviri C. Stress Management Techniques: evidencebased procedures that reduce stress and promote health. HealthSci J. 2011;5(2):16.

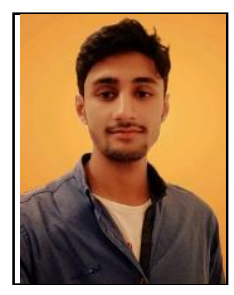

Muhammad Shahid Zafar

Place and date of Birth: Bhakkar, Pakistan 23-31995.

Educational background: $2^{\text {nd }}$ semester HND, The University of Agriculture Peshawar, Pakistan.

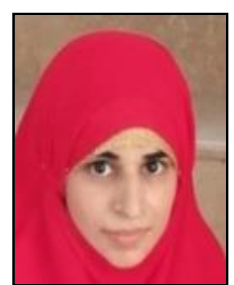

\section{Museera Nauman}

Place and date of Birth: Sawabi, Pakistan 03-041996.

Educational background: $2^{\text {nd }}$ semester HND, The Universityof Agriculture Peshawar, Pakistan.

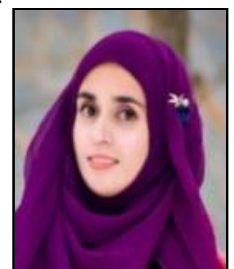

Hina Nauman

Place and date of Birth: Sawabi, Pakistan 20-041998.

Educational background: $2^{\text {nd }}$ semester HND, The Universityof Agriculture Peshawar, Pakistan. 